\title{
A CASE OF CONGENITAL CYST OF LARYNX IN AN INFANT
}

T. Shankar ${ }^{1}$, Srinivas $\mathrm{K}^{2}$, Nagaraj $\mathrm{K}^{3}$, Manish Kumar ${ }^{4}$, S. Muneeruddin Ahmed ${ }^{5}$

\section{HOW TO CITE THIS ARTICLE:}

T. Shankar, Srinivas K, Nagaraj K, Manish Kumar, S. Muneeruddin Ahmed. "A Case of Congenital CYST of Larynx in an Infant". Journal of Evolution of Medical and Dental Sciences 2014; Vol. 3, Issue 45, September 18;

Page: 11045-11050, DOI: 10.14260/jemds/2014/3441

ABSTRACT: INTRODUCTION: Congenital Laryngeal Cysts are a rare cause of neonatal airway obstruction. Most cases of the infants with Stridor are usually evaluated for laryngomalacia, croup, acute laryngotracheobronchitis and vocal cord paralysis. Flexible laryngoscopy in awake infant helps in identifying the cause for respiratory embarrassment. It can be easily managed once diagnosed. It will lead to high morbidity and mortality if one misses the true diagnosis. CASE PRESENTATION: A male infant aged 2 months was brought with the complaints of labored breathing since birth and developing Stridor since 3 days. Flexible awake laryngoscopy was done to diagnose the condition as Cyst of the Larynx. It was excised by micro laryngeal surgery. DISCUSSION: Various authors have classified the cysts of larynx depending upon their cell of origin, site of origin and its route of expansion. They are mainly ductal type and saccus type with or without endodermal elements. Treatment is either by endoscopic excision, marsupialization or excision through an external approach. CONCLUSION: Even though rare Cysts of larynx as a cause of infantile respiratory embarrassment should be kept in mind. Initial aspiration will confirm as well as help in intubation before undertaking micro surgery. Proper planning and total excision of the sac wall allowing the dependent drainage will avoid recurrence.

KEYWORDS: Awake flexible laryngoscopy, saccular cyst, Ductal cyst, Laryngomalacia, marsupialization, obstructive sleep Apnea, micro laryngeal, ventricle of larynx and laryngocele.

CASE REPORT: A 2 month old male infant was brought to the Out Patient department of Government ENT Hospital, Koti, Hyderabad attached to Osmania Medical College, Hyderabad with the presenting complaints of labored breathing since birth and Stridor since 3 days which was more during sleep. There was no history of difficulty in feeding and cyanosis.

The protocol of evaluating infants with such history was adopted by undertaking basic investigations like X-ray chest and hematological parameters; keeping in mind the need for intubation under G.A. Initially awake flexible laryngoscopy was done on the next day.

It showed a laryngeal cyst measuring $2 \times 1.5 \mathrm{Cms}$ and obscuring the laryngeal inlet predominantly occupying the right side. The cyst was smooth, glistening and seemed to arise from medial surface of the aryepiglottic and laryngeal surface of the epiglottis. 
Fig. 1: Showing the Laryngeal cyst.

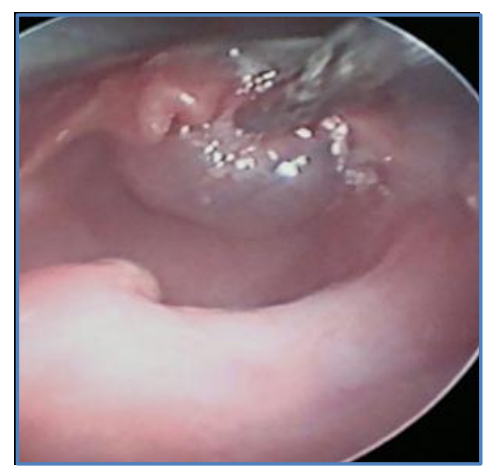

Fig. 1: Epiglottis

As opined by the Anesthetist that intubation would be difficult and since the patient was in inspiratory Stridor, initial aspiration with vide bore needle was done to reduce the size of the cyst. The aspiration was thick straw colored fluid. Then the endotracheal intubation was done. With the help of $0^{0}$ endoscope guidance wall of the cyst was excised and marsupialization was done keeping in mind the dependant drainage. There was minimal bleeding. The specimen sent for Histo Pathology. Patient was extubated immediately after the procedure and postoperative period was uneventful.

Intravenous antibiotics and steroids were given during this period, keeping a watch for difficulty in breathing. After 05 days the patient was discharged and referred to Pediatrician for further management. The HPE report was given as Lymphatic cyst.

Fig. 2: Showing small and large spaces with Stratified Squamous epithelium.

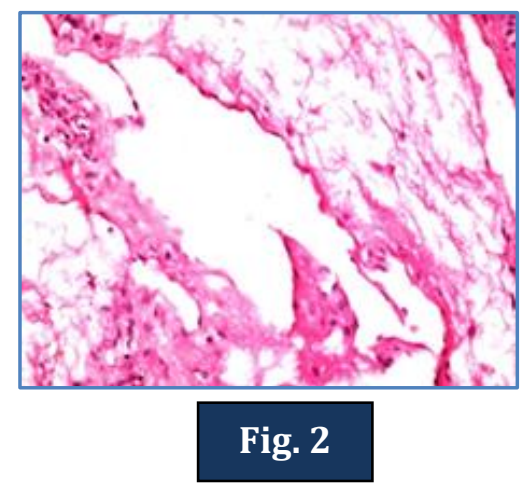

Fig. 3: Showing Surface mucus membrane with sub- mucosal loosely arranged fibro vascular stroma.

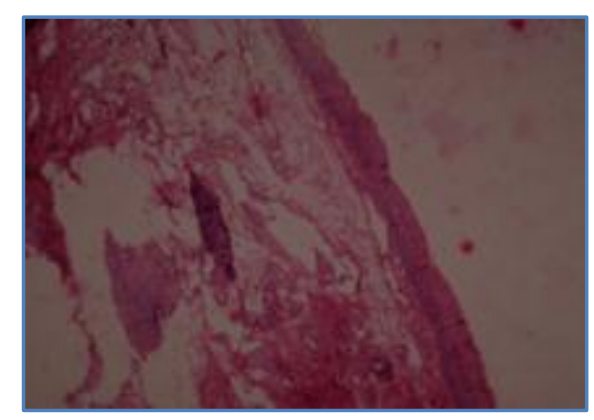

Fig. 3 
Serial sections studied shows stratified squamous surface epithelium, sub-epithelial loose fibro vasular stroma with Numerous, Large and small Lymphatics. Follow-up after 24months revealed a normal developing infant with no voice problems and no difficulties in eating or breathing.

DISCUSSION:(1) Congenital saccular cysts of Larynx are unusual lesions that commonly present with respiratory obstruction in infants and children. $(2,3)$ Congenital Laryngeal Cysts are thought to arise from obstruction of saccular ducts or from atresia of the Saccule itself. Laryngeal Saccule is a small duct arising from ventricle of the Larynx.

It passes between the false vocal cords and the base of the epiglottis and the thyroid cartilage. It contains mucus glands and secretes mucus which drains into the roof of the anterior part of the ventricle. Hence saccular cysts of larynx are developmental failure in maintaining the patency of saccular ducts resulting in stagnation of secretions and cyst formation. They are different from laryngocele that they do not have an opening into the ventricle and they contain mucus.(1)

On the other hand laryngocele is defined as dilatation or herneation of the Saccule and contains air. Laryngeal cysts expand through various structurally weaker areas of the Larynx. Saccular cysts are part of Laryngeal cysts presenting with variable degrees of air way obstruction, hoarseness and dysphagia.(4) The first classification of Laryngeal cystic lesions was described by Desanto et al. The authors divided all Laryngeal cyst in to saccular, ductal, and thyroid cartilage foramina cysts.(5)

In 1997, Arens and Colleagues created a new classification system in which the location of the cyst and Histo-morphology were taken in to consideration. In this classification Laryngeal cyst were classified as congenital, retention or inclusion cysts.(6) Vito Forte from Toronto introduced a new classification system for congenital laryngeal cysts. In Type one Intra laryngeal cysts remain within confines of the larynx (endodermal elements only). In Type II cysts with extra laryngeal extension cysts extend beyond the confines of the larynx were included. A sub type II named as a, where cysts with Endodermal elements only are included.

In Type II b both endodermal and mesodermal elements are included; like laryngotracheal duplication or diverticulum.(5) Classically, congenital laryngeal cysts have been histologically shown to be comprised of squamous or respiratory epithelium with a fibrous stroma (i.e. endodermal derivatives).(6) The Saccule is a membranous pouch located between the ventricular fold and the inner surface of the thyroid cartilage. The normal mucous membrane surface of the Saccule is covered with openings of $60-70$ mucous glands.(7)

Endoscopy is the gold standard for diagnosis of saccular cysts. Endoscopic evaluation reveals a cystic lesion containing thick, mucoid fluid emanating from behind the aryepiglottic fold in the case of lateral cysts, or from the ventricles, and protruding into the laryngeal lumen in the case of anterior cysts. Needle aspiration may be useful in diagnosing the lesion, but drainage of the cyst offers only temporary treatment.(7) Marsupialization may be adequate for the treatment of small saccular cysts.

However, in the case of recurrence of large cysts, endoscopic or open excision of the cyst is required so as to remove the cystic tissue completely. Open surgical approaches for congenital laryngeal cysts have been treatment in terms of healing is complete excision of the cyst.(8) For this reason, some authors recommend a cervical approach in the first intention, especially in case of large cysts, since it offers good extra mucosal exposure of the paralaryngeal space, facilitating cyst excision with minimal morbidity. 
The technique used in all Forte $\mathrm{V}$ cases was an anterior approach midline thyroidotomy. The authors recommend following the cysts to its intra laryngeal origin. The midline thyroidotomy technique has, in their experience, proven to be an effective, safe way to completely remove congenital laryngeal cysts. This new classification system is based on the anatomic extension of the cyst and histopathology. This new system aims to aid the surgeon with surgical management of these cysts, with the goal of avoiding unnecessary open surgical procedures and also to preventing recurrence of the cyst and the need for repeated endoscopic treatments or tracheotomy.

Airway obstructing saccular cysts in adults are rare laryngeal anomalies. Treatment with tracheotomy may be needed for control of the airway. There was no need for a tracheotomy in our patient as a strict protocol is followed in all pediatric patients presenting with labored breathing or Stridor. It should be remembered that if endoscopic excision of the cyst lining is incomplete, secondary scarring and fibrosis at the surgical site may cause expansion of the cyst in a direction away from the fibrosis, along a path of least resistance.

To ensure that simple marsupialization is successful, one must create a wide opening in the cyst wall to allow continued decompression. The location of the cyst opening, the laxity of the tissues at the orifice and the anatomy, can influence the continued patency of the cyst. The cyst should be opened at or near the natural drainage point of the laryngeal Saccule. Our technique entailed endoscopic marsupialization of the cyst without damaging the laryngeal frame work. It is important to save the aryepiglottic fold which helps maintain the architecture of the supra glottic larynx and can possibly decrease the risk of aspiration. ${ }^{(9)}$

Khodael et al. reported a newborn girl who developed marked inspiratory Stridor and respiratory distress immediately after birth. During intubation by a senior anesthetist, a large laryngeal mass was noted in the supra glottic region. In our case, intubation was avoided by the anesthetist and initial aspiration was advised.(10,11) Saccular cysts are rare and few reports on pediatric cases are found. While Stridor in infants is not a rare entity, congenital laryngeal cysts though rare potentially a fatal cause of airway obstruction within minutes after birth. (12) One case of a saccular cyst in a three month - old infant was described by Tosun et al.

The infant presented with severe Stridor and respiratory distress. Direct laryngoscopy of the larynx revealed a Saccular cyst. The Stridor disappeared shortly after surgical excision under direct laryngoscopy.(13) Another two cases of laryngeal cysts in adults, one a giant laryngocele that needed tracheostomy and the other, a large saccular cyst, were described by penning et al.(13) Other case reports are found in small children and some authors favor complete excision by external cervical approach and others are for endoscopic removal of the cysts.

The Prognosis of endoscopic removal of a saccular cyst depends on the specific case and the expertise of the surgical team. It is very rare condition, but as seen in the literature, its prognosis is good. A few authors have described some recurrence after endoscopic procedures and prefer an open external approach. Our case was successful with the endoscopic approach and showed good prognosis with normal voice and swallowing function.

CONCLUSION: Congenital Laryngeal Cysts are rare but can cause respiratory problems in infants and children. Following a strict protocol in evaluating such infants by doing awake flexible endoscopy and preparing oneself to go ahead with either endoscopic or external approach removal to minimize the morbidity and mortality. 
The cysts can be co- associated with laryngomalacia. Endoscopic marsupialization is an effective means of Treatment for ductal cysts and saccular cyst confined to the Larynx.

\section{REFERENCES:}

1. Cotton RT, Prescott CA. Congenital anomalies of Larynx. In: Cotton RT, Myer CM, editors; Practical pediatric Otolaryngology. Philadelphia, PA: Lippincott-Raven-1999, P 508-509.

2. AL Abramson, B Zielinski. Congenital Saccular cysts of the Newborn. Laryngoscope; 1984, vol 94 (12) 1580-1581.

3. PH Holinger, LD Holinger, DR Barnes, LJ Smid. Laryngocele and Saccular Cysts. Annals of Otology; 1978, Vol 87, (5) 675-685.

4. LW Desanto, KD Devine, LH Weiland. Cysts of the Larynx, Classification. Laryngoscope; 1970, Vol.80, (1) 261-267.

5. C Arens, H Glanz, O Kleinsasser. Clinical and Morphological Aspects of Laryngeal Cysts. European Archives of Oto-Rhino-Laryngology, 1997; Vol.254, (9-10) 430-436.

6. V Forte, G Fuoco, A James. A New Classification system for "Congenital Laryngeal Cysts". Laryngoscope; 2004; Vol.114, (6), 1123 - 1127.

7. SM Ahmad, AM Soliman. Congenital Anomalies of the Larynx. Otolaryngologic Clinics of North America; 2007, Vol.40, (1)-177-191.

8. E Ostfeld, Z Hazan, S Rabinson, L Auslander. Surgical Management of Congenital Supraglottic Lateral Saccular cyst. International Journal of Pediatric Otorhinolaryngology; 1990 Vol. 19, (3)289-294.

9. I Khodaei, A Karkanevatos, A Poulios, MS McCormick. Airway obstruction in a Newborn due to a Congenital Laryngeal Cyst. International Journal of Pediatric Otorhinolaryngology, 2007; Extra. Vol.2, (4), 254-256.

10. CA Righini, H Kadaoui, N Morel, C Llerena, E Reyt. Stridor in a Newborn caused by a congenital laryngeal saccular cyst. International journal of Pediatric Otorhinolaryngology Extra, 2006; vol.1, (2), 145-149.

11. Z Hazan, E Ostfeld, S Rabinson, L Auslander. Neonatal Respiratory Distress due to congenital laryngeal cyst. Harefuah, 1990, Vol.119, (11), 371-372.

12. F Tosun, H Soken, Y Ozkaptan. Saccular cyst in an infant, an unusual cause of Life-Threatening Stridor and its surgical treatment. The Turkish journal of pediatrics, 2006; Vol48, (2), 178-180.

13. RJ Pennings, FJ van den Hoogen, H A Marres. Giant Laryngocele, a cause of Upper Airway obstruction. European Archives of Oto-Rhino-Laryngology, Vol.258, (3) 2001, 137 -140. 


\section{AUTHORS:}

1. T. Shankar

2. Srinivas K.

3. Nagaraj K.

4. Manish Kumar

5. S. Muneeruddin Ahmed

\section{PARTICULARS OF CONTRIBUTORS:}

1. Professor, Department of ENT, Osmania Medical College, Hyderabad.

2. Assistant Professor, Department of ENT, Osmania Medical College, Hyderabad.

3. Assistant Professor, Department of ENT, Osmania Medical College, Hyderabad.

4. Assistant Professor, Department of ENT, Osmania Medical College, Hyderabad.
5. Formerly Professor, Department of ENT, Osmania Medical College, Hyderabad.

\section{NAME ADDRESS EMAIL ID OF THE} CORRESPONDING AUTHOR:

Dr. S. Muneeruddin Ahmed,

44/118, $2^{\text {nd }}$ Lane,

Prakash Nagar,

Kurnool-518004.

Email: ahmedmunirent@gmail.com

Date of Submission: 04/09/2014. Date of Peer Review: 05/09/2014.

Date of Acceptance: 11/09/2014.

Date of Publishing: 17/09/2014. 